\title{
Cognitive outcome of early intervention in preterms at 7 and 9 years of age: a randomised controlled trial
}

\author{
Lisbeth Hauglann, ${ }^{1}$ Bjørn Helge Handegaard, ${ }^{2}$ Stein Erik Ulvund, ${ }^{2,5}$ \\ Marianne Nordhov, ${ }^{3,4}$ John A Rønning, ${ }^{4}$ Per Ivar Kaaresen ${ }^{3,4}$
}

For numbered affiliations see end of article.

\section{Correspondence to} Lisbeth Hauglann, Department of Child and Adolescent Psychiatry, Division of Child and Adolescent Health, The University Hospital of North Norway, P.O. Box 19, Tromsø N-9039, Norway; lisbeth.hauglann@hotmail.com

Received 8 April 2014 Revised 1 August 2014 Accepted 7 September 2014 Published Online First 23 September 2014

\begin{abstract}
Objective Examine the effect of an early intervention programme on cognitive outcome at 7 and 9 years in children with birth weight (BW) $<2000 \mathrm{~g}$.

Design A randomised controlled trial of a modified version of the Mother-Infant Transaction Program.

Setting A single tertiary neonatal unit.

Patients 146 infants were randomised into a preterm control group (74) or a preterm intervention group (72). Interventions The intervention consisted of eight sessions shortly before discharge and four home visits by specially trained nurses focusing on the infants' unique characteristics, temperament, developmental potential and the interaction between infants and parents. Main outcome measures Outcomes were assessed with the Wechsler Intelligence Scale for Children (WISC-III).

Results Mean BWs were 1396 (429) g in the intervention group and 1381(436) $\mathrm{g}$ in the control group. After adjusting for the possible clustering effects of twin pairs and maternal education, there were no significant differences in WISC-III scores at age 7 or 9. The mean difference was 4.1 points $(95 \% \mathrm{Cl}-1.5$ to 9.8 points) in favour of the intervention group at 7 years and 2.2 points $(95 \% \mathrm{Cl}-3.4$ to 7.6 points) at 9 years. At 7 years, a 6.8 points difference in the Verbal Comprehension Index ( $95 \% \mathrm{Cl} 0.5$ to 13.0 points) was found in favour of the intervention group. Loss to followup at age 7 and 9 was $11 \%$ and $14 \%$, respectively. Conclusions This intervention programme did not have a sustained significant effect on overall cognitive outcomes in preterm children at age 7 and 9 .

Trial registration number The trial has been registered at http://www.clinicaltrials.gov (identifier NCT00222456).
\end{abstract}

\section{INTRODUCTION}

Preterm infants are at increased risk of developing long-term cognitive and neurobehavioural problems. ${ }^{1}{ }^{2}$ Compared with term-born peers, preterm children have poorer academic achievements, and they often need special educational services in school. $^{34}$ Given the significant risk of neurodevelopmental problems, several early intervention (EI) programmes have been developed to enhance the child's cognitive and neurodevelopmental development. 567 A systematic review of EI programmes showed an overall beneficial effect from various strategies. Positive neurocognitive outcomes were found up to age 3 , followed by a diminishing effect from age $5 .^{8}$ Furthermore, a meta-analysis of EI

\section{What is already known on this topic}

The beneficial effects of early intervention programmes to enhance cognitive development of preterm children remain unclear. There are few randomised controlled trials and research on long-term outcomes is sparse.

\section{What this study adds}

An early intervention programme does not seem to have a prolonged significant influence on cognitive scores (IQ) in preterm children at 7 and 9 years of age. The attenuation of intervention effect is consistent with findings of other long-term studies of preterm children at risk.

programmes found a significant effect on cognitive outcomes at 24 months corrected age. At school age however, there was no longer any effect of the intervention programme on cognitive outcomes. 9 These findings contrast those of a small study by Achenbach et $a l^{1011}$ based on the Mother-Infant Transaction Program (MITP). Achenbach's study found favourable long-term effects on preterm children's cognitive and behavioural development at age 7 and 9. Due to the conflicting results and particularly the limited research on long-term effects of EI programmes, we designed a randomised controlled trial (RCT) with long-term follow-up. The intervention was a modified version of the MITP and theoretically based on the transactional model of development, which emphasises the mutual interdependence between the child and the environment. ${ }^{12}$ According to this model, different biological and environmental risk factors are expected to act in interactive relationships and implies that preterm children's adaptation is shaped by their ongoing daily transactions with the caregiver. ${ }^{13}$ Thus, a more optimised interaction which enables the parents to interpret the infant and act more competently according to the infant's cues may result in a strengthened parent-infant relationship and stimulate the child's later neurocognitive development and competence. ${ }^{12} 13$

Measuring cognitive outcomes is important, as improved cognitive functioning may reduce the 
need for educational support and school failure in these children at risk. We have previously reported favourable effects of this EI programme on cognitive performance at age $5 .{ }^{14} \mathrm{An}$ extended follow-up at school age, when the children are introduced to increasing academic demands, may answer the question whether a brief intervention has effect on cognitive performance later on. Thus, the aim of the present study was to investigate whether an intervention in an early phase of development has beneficial effects on cognitive outcomes in prematurely born children at 7 and 9 years.

\section{METHODS}

\section{Study design}

Details of the study design have been described elsewhere ${ }^{14} 15$ and are only briefly outlined here. Between March 1999 and September 2002, all surviving infants treated at the University Hospital of North Norway (UNN) with a birth weight (BW) $<2000$ g, with no congenital anomalies and whose mothers' first language was Norwegian, were eligible for this study. The infants were randomly assigned to either a preterm intervention (PI) $(n=72)$ or a preterm control (PC) $(n=74)$ group. Randomisation was arranged in random blocks of four and six, using computer-generated random numbers and stratified by gestational age (GA) ( $\leq 28$ and $>28$ ). Because of the nature of the intervention, twins were allocated to the same group and triplets were excluded. The allocation was performed by using sealed opaque envelopes, identified by stratification group and opened after the completion of various questionnaires, and opened by the research nurse. Written informed consent was obtained if the parents agreed to participate. The study was approved by the regional committee for medical research ethics and the Norwegian Data Inspectorate.

\section{Intervention programme}

The intervention programme was a modified version of the MITP. $^{7}$ The modification consisted of an initial debriefing session, where the parents were allowed to share their experiences about the hospital stay and express difficult feelings. Active participation and involvement of both parents were encouraged. After the initial session, the intervention consisted of 1-h daily sessions with both parents and their infant the last 7 days before planned discharge from hospital, at a postmenstrual age of at least 34 weeks. The intervention was carried out by eight specially trained neonatal nurses. Each session addressed aspects of the infant's behaviour such as reflexes, self-regulation and interaction, signs of distress and behavioural states and how parents could bring the infant into a quiet alert state for mutual social interaction. The last two in-hospital sessions focused on the parents' sensitivity and responsiveness in daily caretaking routines.

The daily in-hospital sessions were followed by four home visits by the same intervention nurse at 3, 14, 30 and 90 days after discharge. The home visits explored the family's adjustment to the home environment, interaction between the infants and the parents, how to support and stimulate the infant and evaluation and discussions about the intervention programme. A complete overview of the intervention programme is summarised by Rauh et al. ${ }^{7}$ A detailed log of every intervention visit was kept and was regularly reviewed and supervised by a senior child psychologist (JAR) to maintain the consistency of the intervention. The intervention families did not have access to the intervention nurses outside the scheduled intervention visits. The control group followed the department's standard routines for discharge of preterm infants, which consisted of a clinical examination, including visual and auditory screening, an offer of training in infant massage from the unit's physiotherapist and a discharge consultation with one of the clinicians on the ward. Both groups had access to standard follow-up after discharge.

\section{Baseline data}

Perinatal variables were collected from medical records. GA was determined by ultrasound examinations between 16 and 18 weeks of gestation. The Score for Neonatal Acute Physiology II $^{16}$ and the Clinical Risk Index for Babies ${ }^{17}$ were calculated as a measure of the severity of initial illness. Small for gestational age was defined as BW more than 2 SDs below the mean for GA and gender, based on Norwegian data. ${ }^{18}$ Intraventricular haemorrhage was graded according to Papile ${ }^{19}$ and periventricular leukomalacia was defined by the presence of echolucensis by cerebral ultrasound. Social variables used in the analyses were collected from parents at discharge in a separate questionnaire.

\section{Outcome measures}

The primary outcome of this study was cognitive performance at 7 and 9 years of age and this was assessed by the Norwegian version of Wechsler Intelligence Scale for Children (WISC-III). ${ }^{20}$ This test consists of 13 subtests that are combined into three IQ scores; full scale IQ (FSIQ), verbal IQ (VIQ) and performance IQ (PIQ). Based on the 13 subtests, the following IQ Index scores are summarised; verbal comprehension, perceptional organisation, freedom from distractibility and processing speed. The split-half reliability and test-retest reliability of the WISC-III scores are $>0.93 .^{21}$ The cognitive testing was performed by four specially trained test technicians. All examinations were video-recorded and reviewed regularly to maintain consistent scoring. At 7 and 9 years, medical examination was performed on clinical indication only. All assessments were blinded to the children's group allocation.

\section{Power calculations}

The original power analysis in this study was based on having an $80 \%$ chance of detecting a clinically significant group difference of 7.5 IQ points at age 2, using the Bayley Scale of Infant Development II (power=0.80). This indicated that 64 infants were needed in each preterm group. Allowing for withdrawals, the target sample size was 70 infants in each group.

\section{Statistical analyses}

Linear mixed model (LMM) analysis was used to test for group differences in cognitive outcomes at 7 and 9 years controlling for maternal education. ${ }^{22}$ This method accounts for the potential clustering effect of twin pairs when including family affiliation as a random effect. Differences in continuous variables are given as mean differences with 95\% CIs. Pearson $\chi^{2}$ tests and one-way analysis of variance were used to compare baseline demographic family variables. Group comparisons on demographic child variables were done by LMM analysis. p Values $<0.05$ were considered significant. All tests were 2-sided. All results are reported as intention to treat. Data were analysed by SPSS V.19.0.

\section{RESULTS}

During the study period, a total of 203 infants with a BW $<2000 \mathrm{~g}$ were treated at UNN. This represented $96 \%$ of all infants with BWs $<2000 \mathrm{~g}$ born in the two counties Troms and Finnmark. One hundred and sixty-eight infants fulfilled the inclusion criteria, and 146 infants (87\%) from a total of 130 families were randomised. Sixteen families had both twins 
included in the study. The basic characteristics at the time of randomisation are shown in table 1 . The groups were similar in sociodemographic and neonatal characteristics except for a slight difference in maternal education (mean difference 1.1 years (95\% CI 0.03 to 2.2 years); $p=0.04$ ) in favour of the intervention group (table 1). All mothers in the intervention group participated in every intervention session, whereas the fathers participated in a median of 6 of 12 sessions (IQR: 4-9 sessions). The patient flow until 9 years is shown in figure 1 . The follow-up rates at 7 and 9 years were $89 \%$ and $86 \%$, respectively. Children unable to complete the assessment were withdrawn.

\section{Cognitive outcomes}

The results of cognitive outcomes at 7 and 9 years are presented in tables 2 and 3 , respectively. When adjusting for maternal education and taking the dependency caused by twin pairs into

Table 1 Infant characteristics and social factors at randomisation

\begin{tabular}{|c|c|c|}
\hline Infant characteristics & $\begin{array}{l}\text { Intervention } \\
(\mathrm{N}=72)\end{array}$ & $\begin{array}{l}\text { Control } \\
(\mathrm{N}=74)\end{array}$ \\
\hline BW, mean (SD), g & $1396(429)$ & $1381(436)$ \\
\hline $400-1000$ g, n (\%) & $20(28)$ & $20(27)$ \\
\hline $1001-1500$ g, n (\%) & $15(21)$ & $20(27)$ \\
\hline $1501-2000 \mathrm{~g}, \mathrm{n}(\%)$ & $37(51)$ & $34(46)$ \\
\hline GA, mean, (SD), weeks & $30.2(3.1)$ & $29.9(3.5)$ \\
\hline$<28$ weeks, $\mathrm{n}(\%)$ & $17(24)$ & $19(27)$ \\
\hline 28-32 weeks, n (\%) & $36(50)$ & $37(50)$ \\
\hline$\geq 33$ weeks, n (\%) & $19(26)$ & $18(24)$ \\
\hline $\mathrm{SGA}^{*}(\%)$ & $11(13)$ & $10(14)$ \\
\hline Twins, n (\%) & $16(22)$ & $14(19)$ \\
\hline Prenatal steroids, n (\%) & $53(74)$ & $57(77)$ \\
\hline SNAP-II score, mean (SD) & $8.3(10.9)$ & $10.4(11.3)$ \\
\hline CRIB score, mean (SD) ( $\mathrm{N}=85$ ) & $3.2(2.8)$ & $2.7(2.9)$ \\
\hline Received ventilation, n (\%) & $29(40)$ & $37(50)$ \\
\hline $\begin{array}{l}\text { Duration of ventilation, mean (SD), } d \\
(\mathrm{~N}=66)\end{array}$ & $7.0(18.6)$ & $7.1(17.3)$ \\
\hline Postnatal steroid use, n (\%) & $9(13)$ & $10(14)$ \\
\hline $\begin{array}{l}\text { Oxygen therapy at } 36 \text { weeks of } \\
\text { gestation, } \mathrm{n}(\%)\end{array}$ & $11(15)$ & $14(19)$ \\
\hline \multicolumn{3}{|l|}{ Abnormal cerebral ultrasound, $n(\%)$} \\
\hline IVH grade 1 or 2 & $7(10)$ & $8(11)$ \\
\hline IVH grade 3 or 4 & $3(4)$ & $5(7)$ \\
\hline Periventricular leukomalacia & $4(6)$ & $8(11)$ \\
\hline \multicolumn{3}{|l|}{ Maternal and social characteristics } \\
\hline Mother's age, mean (SD), years & $30.8(6.1)$ & $29.1(6.4)$ \\
\hline Firstborn children, $\mathrm{n}(\%)$ & $40(56)$ & $37(54)$ \\
\hline $\begin{array}{l}\text { Mother's education, mean }(S D) \text {, years } \\
(\mathrm{N}=131) \dagger\end{array}$ & $14.6(2.8)$ & $13.5(3.2)$ \\
\hline $\begin{array}{l}\text { Father's education mean, }(S D) \text {, years } \\
(N=131) \dagger\end{array}$ & $13.8(3.1)$ & $13.5(3.2)$ \\
\hline Mother's monthly income & $15.8(7.7)$ & $14.6(6.7)$ \\
\hline Father's monthly income $\ddagger$ & $21.1(8.7)$ & $19.9(8.1)$ \\
\hline \multicolumn{3}{|c|}{$\begin{array}{l}\text { SNAP-II indicates the Score for Neonatal Acute Physiology II (includes mean blood } \\
\text { pressure, lowest temperature, P02/fraction of inspired oxygen ratio, serum pH, } \\
\text { multiple seizures and urine output); CRIB, Clinical Risk Index for Babies (includes BW, } \\
\text { GA, congenital malformations, maximal base deficits in the first } 12 \mathrm{~h} \text {, minimal } \\
\text { appropriate fraction of inspired oxygen in the first } 12 \mathrm{~h} \text { and maximal appropriate } \\
\text { fractions of inspired oxygen in the first } 12 \mathrm{~h} \text { ). } \\
\text { *SGA, defined as a BW }>2 \text { SD below the mean for GA. } \\
\text { tCalculated for } 131 \text { families due to } 15 \text { twin pairs. } \\
\text { ₹Average monthly income (SD) in } 1000 \text { Norwegian kroner. } \\
\text { BW, birth weight; GA, gestational age; IVH, intraventricular haemorrhage; SGA, small } \\
\text { for gestational age. }\end{array}$} \\
\hline
\end{tabular}

account, there were no significant differences between the PI and PC groups in FSIQ, VIQ and PIQ scales. However, the observed means in the PI group were consistently higher than in the PC group for all measures on both occasions. A notable difference was found at 7 years, where the PI group scored significantly higher on the Verbal Comprehension Index; nevertheless, there were no significant differences on the other WISC-III Index scores at 7 and 9 years.

\section{DISCUSSION}

The main purpose of this study was to examine the effect of a parent- sensitising intervention in the hospital-home transition on preterm children's cognitive performance at 7 and 9 years. The results showed that the MITP did not have a sustained effect on preterm children's overall cognitive performance at 7 and 9 years of age. The PI group scored consistently higher than the PC group on the FSIQ, VIQ and PIQ. However, the only significant difference was found on the Verbal Comprehension Index at 7 years.

These results are not in line with our previous finding of significantly higher IQ scores at 5 years in favour of the intervention group. ${ }^{14}$ At 5 years, this difference was within a clinically significant range, which was considered to be more than 5 points. ${ }^{23}$ According to the transactional model, development is viewed to be cumulative, meaning that the effects of an intervention may emerge in the course of time. ${ }^{12}$ Based on this theoretical model, a larger effect could have been expected in the present study.

Although we did not find any significant differences between the groups in the overall IQ scores, the PI group scored consistently higher than the PC group on all measurements. At 7 years, the differences in the IQ scores were in the range of 4-5 points with relatively large CIs. These differences might be clinically relevant and the lack of significance might be due to lack of power as this study was designed to detect a difference of 0.5 SD or about 7.5 points. As such, the analyses were slightly underpowered according to the original goals. Loss to follow-up and dependency in the data due to twin pairs have reduced power to detect such an effect to a minimum of 0.76 . However, at 9 years the observed group differences were further reduced to only 1-2 IQ points, and this attenuation over time is in line with two meta-analyses ${ }^{8} 24$ which could not find beneficial effects of intervention after 5 years. The Infant Health and Development Program found beneficial effects of their intervention on cognitive outcome at 3 years, but reported no significant difference at 5 and 8 years of age. ${ }^{25}$ However, improved cognitive scores were found within the heavier preterm infants with a BW $>2000 \mathrm{~g}$ at 8 years. A similar tendency was reported by the Avon Premature Infant Project. They reported that the small effect on cognitive scores at 2 years was no longer detected at 5 years. ${ }^{26}$ The only study that has reported an increased effect on cognitive outcome over time is the Vermont study. ${ }^{10}{ }^{11}$ They reported an effect of the MITP on cognitive outcome at 7 and 9 years, and this was interpreted as an improved parent-child relationship resulting in a cumulative positive effect consistent with the transactional model. ${ }^{12}$ However, the sample size was rather small and included relatively healthy moderately preterm infants born in the presurfactant period, which might limit the generalisation of their results. Interestingly, children in the PI group had significantly higher scores at the Verbal Comprehension Index measured at 7 years. VIQ is found to be more influenced by the children's background, knowledge learnt from the environment and cultural experiences, ${ }^{27} 28$ whereas biological factors are more related to perceptual-performance 


\section{Original article}

Figure 1 Study_flow_diagram.

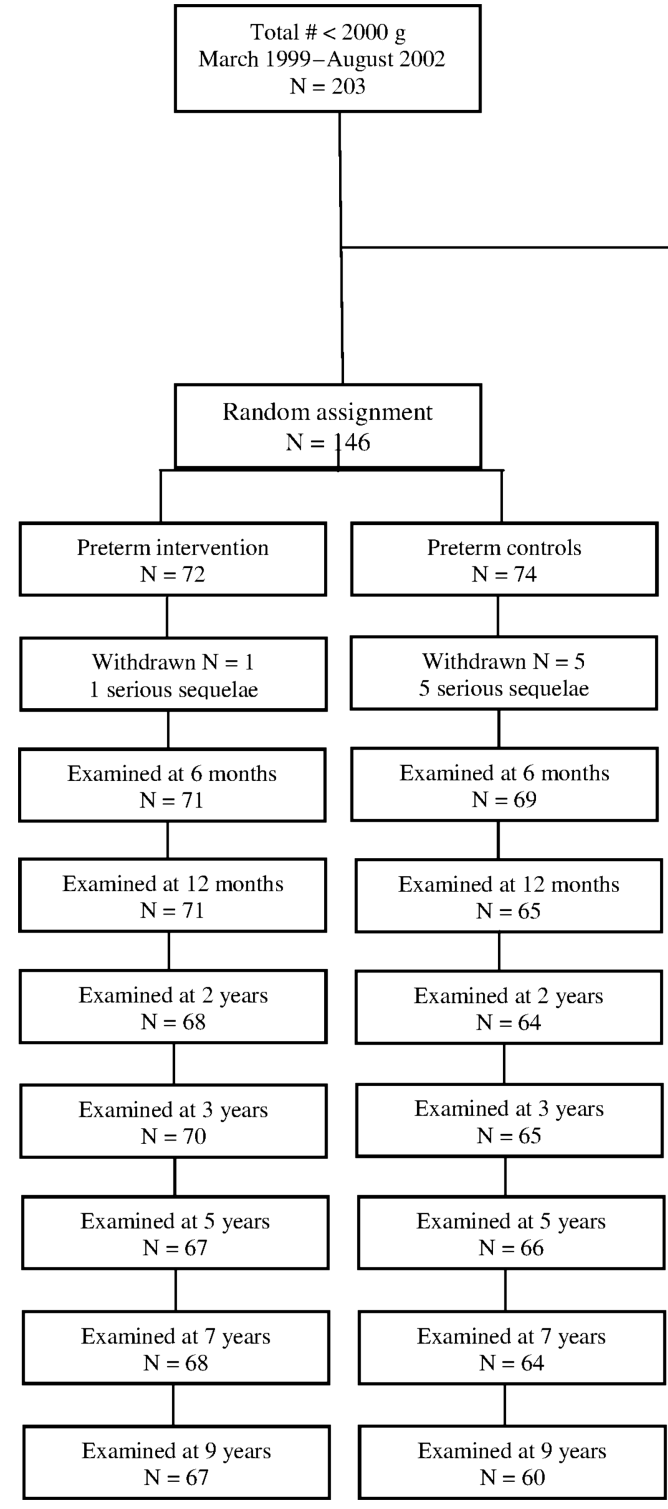

outcomes. $^{29}$ In line with this knowledge, we adjusted the analyses for maternal education as the mothers in the PI group had slightly longer education than mothers in the PC group had. After controlling for this factor, the significant difference between the children's verbal abilities might suggest a more optimised parent-child relationship, which in turn has contributed to improved verbal comprehension abilities at 7 years. Verbal functions as reflected in the ability to form verbal concepts, listen to questions, reason and create thoughts are important skills in an academic setting. However, the practical implication of these test scores in terms of their actual academic functioning in school remains to be more studied.

Table 2 Cognitive outcomes at 7 years of age

\begin{tabular}{|c|c|c|c|c|}
\hline & $\begin{array}{l}\text { Intervention } \\
\text { Mean (SD) } \\
(\mathrm{N}=68)\end{array}$ & $\begin{array}{l}\text { Control } \\
\text { Mean (SD) } \\
(\mathrm{N}=62)\end{array}$ & $\begin{array}{l}\text { Adjusted mean } \\
\text { difference } \\
(95 \% \mathrm{Cl})^{*}\end{array}$ & p Value* \\
\hline Full scale IQ score & $96.3(14.6)$ & $91.5(17.8)$ & $4.1(-1.5$ to 9.8$)$ & 0.15 \\
\hline Total verbal IQ score & $98.6(15.8)$ & $92.8(18.8)$ & $5.0(-1.0$ to 11.1$)$ & 0.10 \\
\hline Total performance IQ score & $94.2(15.8)$ & $91.8(15.9)$ & $1.8(-3.8$ to 7.4$)$ & 0.52 \\
\hline Verbal Comprehension Index & $100.1(15.8)$ & $92.6(20.1)$ & $6.8(0.5$ to 13.0$)$ & 0.035 \\
\hline Perceptual Organisational Index & $94.6(14.9)$ & $92.8(15.4)$ & $1.0(-4.3$ to 6.3$)$ & 0.71 \\
\hline Freedom from distractibility & $94.8(16.5)$ & $91.9(20.4)$ & 2.0 (-4.4 to 8.4$)$ & 0.54 \\
\hline Processing Speed Index & $97.2(14.5)$ & 93.5 (17.2) & $3.8(-1.8$ to 9.4$)$ & 0.18 \\
\hline
\end{tabular}


Table 3 Cognitive outcomes at 9 years of age

\begin{tabular}{|c|c|c|c|c|}
\hline & $\begin{array}{l}\text { Intervention } \\
\text { Mean (SD) } \\
(\mathrm{N}=66)\end{array}$ & $\begin{array}{l}\text { Control } \\
\text { Mean (SD) } \\
(\mathrm{N}=59)\end{array}$ & $\begin{array}{l}\text { Adjusted mean } \\
\text { difference } \\
(95 \% \mathrm{Cl})\end{array}$ & p Value* \\
\hline Full scale IQ score & $100.9(14.3)$ & $98.2(16.6)$ & $2.12(-3.4$ to 7.6$)$ & 0.45 \\
\hline Total verbal IQ score & $102.7(13.7)$ & $99.69(16.3)$ & $2.4(-2.9$ to 7.8$)$ & 0.37 \\
\hline Total performance IQ score & $98.7(17.7)$ & $97.2(15.8)$ & $1.1(-4.9$ to 7.2$)$ & 0.71 \\
\hline Verbal Comprehension Index & $104.1(13.8)$ & $100.1(15.6)$ & $3.5(-1.8$ to 8.7$)$ & 0.19 \\
\hline Perceptual Organisational Index & $99.8(17.1)$ & $98.4(15.3)$ & $0.8(-5.0$ to 6.6$)$ & 0.78 \\
\hline Freedom from distractibility & $97.2(14.5)$ & $96.4(15.1)$ & $0.5(-5.0$ to 5.9$)$ & 0.86 \\
\hline Processing Speed Index & $94.9(16.2)$ & $92.8(20.0)$ & $2.2(-4.3$ to 8.7$)$ & 0.51 \\
\hline
\end{tabular}

The means presented are estimated marginal means from a linear mixed model that adjusts for mother education and the clustering effect of twins.

${ }^{*}$ Adjusted for clustering effects of twin pairs and maternal education.

Additionally, we think it is reasonable to assume that school plays an important role for children at these ages. We speculate whether being in a structured educational environment itself might have contributed to attenuate the differences between the preterm groups as they are exposed to multiple sources of stimuli, both intellectually and socially, and in fact spend more time outside their family environment.

Methodological strengths of this study were the recruitment from a geographically defined area, and that almost all preterm infants born in the area (96\%) were eligible for inclusion making this study a population-based RCT. Our follow-up rate is high in a long-term follow-up study, which strengthens the validity and generalisability of the results. A possible weakness was that BW rather than GA was used as inclusion criterion. Consequently, this rendered more mature growth-restricted infants to be included in the study, making conclusions more difficult to generalise. However, the growth-restricted infants were evenly distributed among the groups, limiting the influence on group differences in the study.

\section{CONCLUSION}

Benefits of EIs on cognitive outcome are reported in various studies at infant and preschool age, but long-term improvements are not consistently found. Our results show diminishing effects of this EI as the preterm children develop and enter the school system. We conclude that this EI programme did not a have a sustained significant effect on cognitive outcomes at age 7 and 9.

\section{Author affiliations \\ ${ }^{1}$ Division of Child and Adolescent Health, Department of Child and Adolescent Psychiatry, University Hospital of North Norway, Tromsø, Norway \\ ${ }^{2}$ Regional Centre for Child and Youth Mental Health and Child Welfare, The Arctic University of Norway, Tromsø, Norway \\ ${ }^{3}$ Pediatric Department, University Hospital of North Norway, Tromsø, Norway \\ ${ }^{4}$ Pediatric Research Group, Faculty of Health Sciences, The Arctic University of Norway, Tromsø, Norway \\ ${ }^{5}$ Department of Educational Research, University of Oslo, Oslo, Norway}

Acknowledgements We thank the families and children for participating in this study, the interventional nurses and in particular the coordinating nurse, Jorunn Tunby.

Contributors LH planned this study, carried out the data analyses, drafted the initial and wrote the final manuscript submitted. BHH carried out the analyses, commented on methodological issues and critically reviewed the manuscript. SEU conceptualised and designed the study and critically reviewed the manuscript. MN contributed to the data collection and critically reviewed the manuscript. JAR conceptualised and designed the study and critically reviewed the manuscript. PIK designed the study and critically reviewed and revised the manuscript; and all authors approved the final manuscript as submitted.
Funding Division of Child and Adolescent Health, Department of Child and Adolescent Psychiatry, The University Hospital of North-Norway. The study is supported by grants from the 'Mental Health Research Program' by Norway Regional Health Authority (Helse Nord RHF).

Competing interests None.

Patient consent Obtained.

Ethics approval The regional committee for medical and health research ethics in Norway.

Provenance and peer review Not commissioned; externally peer reviewed.

\section{REFERENCES}

1 Aylward GP. Neurodevelopmental outcomes of infants born prematurely. J Dev Behav Pediatr 2005;26:427-40.

2 Dahl LB, Kaaresen PI, Tunby J, et al. Emotional, behavioral, social, and academic outcomes in adolescents born with very low birth weight. Pediatrics 2006;118:449-59.

3 Elgen I, Sommerfelt K, Markestad T. Population based controlled study of behavioural problems and psychiatric disorders in low birthweight children at 11 years of age. Arch of Dis Child Fetal and Neonatal Ed 2002;87:F128-321.

4 Johnson S, Wolke D, Hennesy E, et al. Educational outcomes in extremely preterm children: neuropsychological correlates and predictors of attainment. Dev Neuropsychol 2011;36:74-95.

5 McCormick MC, McCarton C, Brooks-Gunn J, et al. The Infant Health and Development Program: interim summary. J Dev Behav Pediatrics 1998; 19:359-70.

6 Koldewijn KM, Wolf MJ, van Wassanear A, et al. The Infant Behavioral Assessment and Intervention Program to support preterm infants after hospital discharge: a pilot study. Dev Med Child Neurol 2005;47:105-12.

7 Rauh VA, Nurcombe B, Achenbach TM, et al. The Mother-Infant Transaction Program. The content and implication of an intervention for mothers of low-birthweight infants. Clin Perinatol 1990;17:31-45.

8 Vanderveen JA, Bassler D, Robertson CMT, et al. Early interventions involving parents to improve neurodevelopmental outcomes of premature infants: a meta-analysis. J Perinatol 2009;29:343-51.

9 Spittle AJ, Orton J, Andersen P, et al. Early developmental intervention programs post hospital discharge to prevent motor and cognitive impairment in preterm infants (Review). Cochrane Database Syst Rev 2012;(12):CD005495.

10 Achenbach TM, Phares V, Howell CT, et al. Seven-year outcome of the Vermont Intervention Program for low-birthweight infants. Child Dev 1990;61:1672-81.

11 Achenbach TM, Howell CT, Aoki MF, et al. Nine-year outcome of the Vermont Intervention Program for low birth-weight infants. Pediatrics 1993;91:45-55.

12 Sameroff AJ. Models of developmental risk. New York, NY: Guildford, 1993.

13 Sameroff AJ, Mackenzie MJ. Research strategies for capturing transactional models of development: the limits of the possible. Dev Psychopathol 2003;15:613-40.

14 Nordhov SM, Rønning JA, Dahl LB, et al. Early intervention improves cognitive outcomes for preterm infants: randomized controlled trial. Pediatrics 2010;126:1088-94.

15 Kaaresen PI, Rønning JA, Ulvund SE, et al. A randomized, controlled trial of the effectiveness of an early-intervention program in reducing parenting stress after preterm birth. Pediatrics 2006;118:e9-19.

16 Richardson DK, Cocoran JD, Escobar GJ, et al. SNAP-II and SNAPPE-II: simplified newborn illness severity and mortality risk scores. J Pediatrics 2001;138:92-100. 


\section{Original article}

17 [No authors listed]. The CRIB (Clinical Risk Index for babies) score: a tool for assessing initial neonatal risk and comparing performance of neonatal intensive care units. International Neonatal Network. Lancet 1993;342:193-8.

18 Skjaerven R, Gjessing HK, Bakketeig LS. Birthweight by gestational age in Norway. Acta Obstet Gynecol Scand 2000;79:440-9.

19 Papile LA, Burstein R, Koffler H. Incidence and evolution of subependymal and intraventricular hemorrhage: a study of infants with birthweights less than 1500 gm. J Pediatr 1978:92:529-43.

20 Wechsler D. Manual for the Wechsler Intelligence Scale for Children. 3rd edn. San Antonio, TX: The Psych Corpor, 2003.

21 Wechsler D. Manual for the Wechsler Intelligence Scale for Children. 3rd edn. London: The Psych Corpor, 1992.

22 West BL, Welch KB, Galecki AT. Linear mixed models: a practical guide using statistical software. Boca Raton, FL: Chapman \& Hall/CRC, 2007.

23 Vohr BR, Poindexter BB, Dusick AM, et al. Beneficial effects of breast milk in the neonatal intensive care unit on the developmental outcome of extremely low birth weight infants at 18 months of age. Pediatrics 2006;118:e115-23.
24 Orton J, Spittle A, Doyle L, et al. Do early intervention programmes improve cognitive and motor outcomes for preterm infants after discharge? A systematic review. Dev Med Child Neurol 2009;51:851-9.

25 McCarton CM, Brooks-Gunn J, Wallace IF, et al. Results at age 8 years of early intervention for low- birth- weight premature infants: the Infant Health and Development program. JAMA 1997;277:126-32.

26 Johnson S, Ring W, Anderson P, et al. Randomized trial of parental support for families with very preterm children: outcome at 5 years. Arch Dis Child 2005;90:909-15.

27 Koeppen-Schomerus G, Eley TC, Wolke D, et al. The interaction of prematurity with genetic and environmental influences on cognitive development in twins. J Pediatr 2000;137:527-33.

28 Pfeiffer SI, Aylward GP. Outcome for preschoolers of very low birth weight: sociocultural and environmental influences. Percept Mot Skills 1990;70:1367-78.

29 Rowe DC, Jacobsen KC, Van den Oord EJ. Genetic and environmental influences on vocabulary IQ: parental education level as moderator. Child Dev 1999;70:1151-62. 